\title{
Social Signals Regulate Gonadotropin-Releasing Hormone Neurons in the Green Treefrog
}

\author{
Sabrina S. Burmeister ${ }^{a}, b \quad$ Walter Wilczynski ${ }^{a}$ \\ alnstitute for Neuroscience, University of Texas at Austin, Austin, Tex.; ${ }^{b}$ Department of Psychology, \\ Stanford University, Stanford, Calif., USA
}

\section{Key Words}

GnRH · Amphibian · Treefrog • Acoustic communication • Androgens $\cdot$ Supplementary reproductive cue

\begin{abstract}
Animals coordinate their physiological state with external cues to appropriately time reproduction. These external cues exert effects through influences on the gonadotropin-releasing hormone neurons (GnRH), at the apex of the hypothalamus-pituitary-gonad (HPG) axis. In green treefrogs, mating calls are important regulators of reproductive behavior and physiology. Reception of mating calls causes an increase in androgen levels, and androgens promote the production of mating calls, demonstrating a mutual influence between the communication and endocrine systems. In order to investigate the central nervous system correlates of social regulation of the HPG axis in green treefrogs, we exposed males to a mating chorus or a control stimulus (tones), counted the resulting number of septo-preoptic $\mathrm{GnRH}$-immunoreactive cells (GnRH-ir), and measured changes in plasma androgens. We found that reception of the mating chorus caused an increase in the number of $\mathrm{GnRH}$-ir cells. As previously shown, we also found that the reception of the mating chorus resulted in higher androgen levels, suggesting that the higher $\mathrm{GnRH}$-ir cell number represents increased $\mathrm{GnRH}$ production and release. We sug-
\end{abstract}

gest that mating calls are an important supplementary cue that promotes $\mathrm{GnRH}$ production and release within the context of $\mathrm{GnRH}$ regulation by seasonal cues. Previous studies have proposed a neuroanatomical link between the anuran auditory system and $\mathrm{GnRH}$ neurons. Our results demonstrate a functional role for this proposed sensory-endocrine circuit, and show for the first time an influence of acoustic signals on GnRH neurons.

Copyright $\odot 2005$ S. Karger AG, Basel

\section{Introduction}

To time reproduction appropriately, animals tie physiological changes to cues in the external environment that predict propitious breeding periods. In seasonal breeders, this is manifest in the annual pattern of gonadal maturation and reproductive behavior that is controlled primarily by photoperiod [Ebling and Cronin, 2000; Dawson et al., 2001]. In addition to such predictive cues as photoperiod, supplemental cues are used by seasonal breeders to modify the precise timing of reproduction based on recent events [such as a changing food supply; Hahn, 1995], and in opportunistic breeders these types of cues may exert primary control over the timing of reproduction [Hau, 2001]. In social animals, interactions with conspecifics often provide important supplemental cues that in some cases suppress [Francis et al., 1993; van der Westhuizen et

\begin{tabular}{|c|c|}
\hline KARGER & (c) 2005 S. Karger AG, Basel \\
\hline $\begin{array}{l}\text { Fax +4161306 } 1234 \\
\text { E-Mail karger@karger.ch } \\
\text { www.karger.com }\end{array}$ & $\begin{array}{l}\text { Accessible online at: } \\
\text { www. karger.com/bbe }\end{array}$ \\
\hline
\end{tabular}

Sabrina S. Burmeister

Department of Psychology, Stanford University

450 Serra Mall, Bldg. 420

Stanford, CA 94305 (USA)

Tel./Fax +1 650723 0881, E-Mail sabrina@psych.stanford.edu 
al., 2002] and in others activate [Lehrman, 1965; Cheng, 1986; Rissman, 1992] the reproductive axis. Green treefrogs (Hyla cinerea) are highly social seasonal breeders and, thus, are an excellent model for studying how conspecific social cues influence reproductive physiology.

In green treefrogs, social signals in the form of mating calls are an important regulator of behavior [Gerhardt, 1987; Gerhardt et al., 1987] and reproductive physiology [Burmeister and Wilczynski, 2000], and these changes in physiology influence the display of social signals, i.e., mating calls [Burmeister and Wilczynski, 2001]. During the summer, male treefrogs gather nightly to call to attract females, which do not, themselves, produce mating calls. In these nightly lek-like aggregations, males interact intensely with other males whose calls together create a chorus. Males compete with their neighbors in the chorus for the attention of females. However, an individual male also depends on his neighbors because a male calling alone is unlikely to attract a female [Gerhardt et al., 1987]. Therefore, an individual male requires the social context of the chorus to be successful in attracting a female with his own calls. This dependence on the social environment is also reflected in the behavioral mechanism of chorus formation whereby calling by one male elicits calls from another (i.e., evoked calling). Although some basic environmental conditions must be met for calling, on a nightly basis, hearing calls is the most potent factor in inducing calling in a variety of anurans [Brooke et al., 2000; Oseen and Wassersug, 2002]. Importantly, the effect of hearing calls goes beyond the elicitation of behavioral responses to the endocrine system, where the implications are far-reaching; experimentally elevated call exposure increases androgen secretion [Burmeister and Wilczynski, 2000], and experimentally elevated androgens increases calling [Burmeister and Wilczynski, 2001]. Thus, in $H$. cinerea, the communication system and endocrine system are intricately linked.

Our previous findings suggest that reception of mating calls functions to maintain reproductive competence during the breeding season [Burmeister and Wilczynski, 2000]. This interpretation is consistent with findings in the grass frog, where reception of mating calls maintain gonad weight in the laboratory, whereas the gonads of males listening to altered calls regress [Brzoska and Obert, 1980]. Therefore, social signals in $H$. cinerea appear to act as supplementary cues for regulating seasonal reproduction. Findings in a variety of species suggest this is a general phenomenon among male and female anurans [Brzoska and Obert, 1980; Chu and Wilczynski, 2001; Lea et al., 2001].
Given that mating calls induce androgen secretion and that androgen levels are controlled by the hypothalamuspituitary-gonad (HPG) axis, it is natural to ask: What are the central nervous system correlates of social control of androgen levels? This question directs our attention to the gonadotropin-releasing hormone $(\mathrm{GnRH})$ neurons which are at the apex of the HPG axis of all vertebrates. To address this question, we exposed male treefrogs to a mating chorus or a control stimulus (tones) and assessed the resulting number of GnRH-immunoreactive cells. To assist in our interpretation of differences in $\mathrm{GnRH}$ immunoreactivity (which alone do not reveal whether more or less $\mathrm{GnRH}$ is being released), we also measured changes in plasma androgens.

\section{Materials and Methods}

The research presented here was described in Animal Research Protocol No. 00050201 approved by the Institutional Animal Care and Use Committee of the University of Texas at Austin.

\section{Experimental Design}

General procedures followed those described in Burmeister and Wilczynski [2000]. Breeding male Hyla cinerea were purchased from Charles Sullivan Co. (Nashville, Tenn., USA). We housed males individually in acoustic chambers (internal dimensions: $14 \times 14 \times$ $20 \mathrm{~cm}$ ), which were equipped with a speaker, microphone, water dish, artificial foliage, and light ( $14 \mathrm{~h}$ light, $10 \mathrm{~h}$ dark). Each night for 10 days, we presented males with a conspecific chorus $(n=9)$ or an array of tones $(n=8)$. The chorus was a 12-min recording of a naturally breeding population in central Texas. We created the tone stimulus by replacing every frog call in the chorus with a tone of the same duration and approximate amplitude as the call it replaced. Tones were within the hearing range of the species, but excluded frequencies that are important in conspecific communication. For a detailed description of stimuli, see Burmeister and Wilczynski [2000]. The stimulus played for $5 \mathrm{~h}$ each night from 21:00 to 02:00 (stimulus onset $1 \mathrm{~h}$ after lights out).

We collected blood by heart puncture on the day the experiment began, and, at the end of acoustic exposure, we collected trunk blood following rapid decapitation. We centrifuged blood promptly, and stored plasma at $-20^{\circ} \mathrm{C}$ until radioimmunoassay. Brains were fixed for $12 \mathrm{~h}$ in Zamboni's fixative (4\% paraformaldehyde, 3\% sucrose, $7.5 \%$ picric acid in $0.1 \mathrm{M}$ phosphate buffer) at $4{ }^{\circ} \mathrm{C}$, followed by storage in $30 \%$ sucrose in phosphate buffer until sectioning.

\section{Immunocytochemistry}

Brains were cryosectioned in the transverse plane at $50 \mu \mathrm{m}$ and stored in phosphate buffered saline (PBS) until immunocytochemistry. Free-floating sections were processed using procedures modified from Ebersole and Boyd [2000]. All reactions were performed at room temperature, unless otherwise noted. Prior to incubation with the primary antibody, sections were treated sequentially as follows: PBS (5 min), $1 \% \mathrm{H}_{2} \mathrm{O}_{2}$ (15 min), PBS (5 min), $0.1 \% \mathrm{NaBH}_{4}(15 \mathrm{~min}$ ), PBS $(3 \times 5 \mathrm{~min})$, and $20 \%$ normal goat serum $(10 \mathrm{~min})$. Sections 
were incubated in the primary antibody (1:800; anti-GnRH raised in rabbit; DiaSorin, Stillwater, MN) in PBS with $0.3 \%$ Triton X-100 (PBST) for $48 \mathrm{~h}$ at $4{ }^{\circ} \mathrm{C}$. The antibody we used was raised against the mammalian form of GnRH [GnRH1 sensu Fernald and White, 1999], and specificity of this antibody for amphibian septo-preoptic GnRH neurons has previously been established [Ebersole and Boyd, 2000]. Sections were then rinsed in PBST $(3 \times 10 \mathrm{~min})$, incubated for $1 \mathrm{~h}$ with goat anti-rabbit biotinylated secondary antibody (1:400; Vector Laboratories, Burlingame, Calif., USA), rinsed in PBST $(3 \times$ $10 \mathrm{~min}$ ), incubated for $1 \mathrm{~h}$ in avidin-biotin complex (Vector Laboratories), and rinsed in PBST $(3 \times 10 \mathrm{~min})$. Antibody binding was visualized with $0.05 \%$ diaminobenzidine tetrachloride (Sigma-Aldrich, Milwaukee, Wisc., USA) with $0.1 \% \mathrm{H}_{2} \mathrm{O}_{2}$ for $5 \mathrm{~min}$. The color reaction was terminated by phosphate buffer rinses $(2 \times 10 \mathrm{~min})$. Sections were mounted onto slides, dehydrated, cleared in xylenes, and covered with Permount and coverslips. Four groups of brains, each with representatives from the chorus and tones groups, were processed sequentially. We accounted for batch-to-batch variation in our statistical model (see below).

We estimated the number of individual GnRH-ir cells by counting all apparent cell profiles (i.e., cell cross sections) with a $20 \times$ objective while blind to treatment. We counted cell profiles either with or without the aid of a camera lucida, depending on availability. As data were collected in random order, a similar number of subjects from each treatment group was counted using the two methods (for chorus group, 4 with and 5 without camera lucida; for tones group, 3 with and 5 without camera lucida). The use of the camera lucida influenced the absolute, but not relative, number of cells counted, and we accounted for this variation in the statistical model (see below).

\section{Radioimmunoassay}

A commercially available radioimmunoassay kit (Amersham Pharmacia Biotech, Piscataway, N.J., USA) was used to measure androgens as follows [for validation of the kit for $H$. cinerea plasma see Burmeister and Wilczynski, 2001]. In order to calculate recoveries for individual samples, we added approximately $2500 \mathrm{cpm}$ of ${ }^{3} \mathrm{H}-$ labeled testosterone to each sample prior to ether extraction. Steroids were extracted from plasma with diethyl ether $(2 \times 3 \mathrm{ml})$, and ether fractions were collected after freezing water fractions in an acetonedry ice bath. Ether fractions were dried with $\mathrm{N}_{2}$, and residues were then dissolved with assay buffer. We assayed samples in duplicate according to assay protocol, and separation of bound and free counts was achieved by the addition of dextran-coated charcoal. We processed known amounts and water blanks through the entire procedure. We adjusted results for recovery and report results as $\mathrm{ng} / \mathrm{ml}$ plasma.

Average recoveries for ${ }^{3} \mathrm{H}$-testosterone were $90 \%$. All samples were run in a single assay and intra-assay variation was $3.4 \%$. The antiserum has $100 \%$ cross reactivity with testosterone, $45-50 \%$ with $5 \alpha$ dihydrotestosterone, $7.1 \%$ with $5 \alpha$-androstane- $3 \mathrm{~b} \alpha, 17 \beta$-diol, and less than $5.0 \%$ for other steroids. The lower limit of detection (2 standard deviations at zero dose) is approximately $3 \mathrm{pg}$ (as per assay specifications). Sensitivity of the assay based on actual recoveries and plasma volume was $1.3 \mathrm{ng} / \mathrm{ml}$ plasma. We were able to obtain samples both before and after acoustic treatment for 7 males in each group.

\section{Behavior}

We recorded the occurrence of calling behavior continuously during the 10 days of acoustic exposure using an automated call detec- tion system [for details see Burmeister and Wilczynski, 2000]. The call detection system counted the number of calls in $15 \mathrm{~min}$ bins. From these counts, we calculated the calling rate (calls per minute) during stimulus presentation (stimulus evoked calling rate), and that which occurred spontaneously at all other times (spontaneous call rate).

\section{Statistics}

To test for the influence of acoustic stimulus on GnRH-ir cell number, we performed an analysis of variance (ANOVA) with microscope method (i.e., with or without camera lucida) and histological processing batch (1-4) as variables in order to account for variation introduced by methodology (i.e., three-factor ANOVA with stimulus, microscope, and batch as independent factors). We present the GnRH-ir cell number data graphically, therefore, as the estimated marginal means as this most accurately reflects the effect tested in the model. Non-adjusted means are also reported. To analyze changes in androgen levels in response to the chorus, we conducted a repeated measures ANOVA on androgen levels before and after stimulus exposure (i.e., time). To test for covariation of GnRH-ir and androgens or calling while accounting for variation due to microscope and batch, we conducted analysis of covariance with microscope and batch as factors and androgen level or calling rate as covariates. We also examined covariation between androgen levels and calling behavior with Pearson's correlation. In all ANOVA models we used Type III Sums of Squares.

\section{Results}

As in other amphibians [Rastogi et al., 1998], in $H$. cinerea, GnRH-ir cells were distributed along the midline of the basal forebrain in the region of the lateral septum and diagonal band. In the mid-sagittal plane, the population forms a shape reminiscent of the letter ' $\mathrm{C}$ '. Thus, in the most caudal distribution of GnRH-ir cells, the ventral and dorsal parts of the population become discontinuous with one another. At this level, the GnRH cells are associated, ventrally, with the most anterior part of the preoptic area, and, more dorsally, with the medial septum. Varicose fibers characteristic of $\mathrm{GnRH}$ neurons appeared throughout the telencephalon. Areas of dense fibers were observed in the midline of the forebrain where the GnRH cell bodies were, the medial and lateral amygdala, and throughout the preoptic area. Most GnRH fibers joined the medial forebrain bundle en route to the median eminence where they are presumably neurosecretory. Fibers were observed throughout the ventral hypothalamus, with lighter fiber staining observed in the medial pallium, thalamus, optic tectum, and tegmentum. No cell bodies were observed in the midbrain where GnRH2 (i.e., chicken GnRH-II) is known to be expressed in anurans [Licht et al., 1994; Rastogi et al., 1998]. 

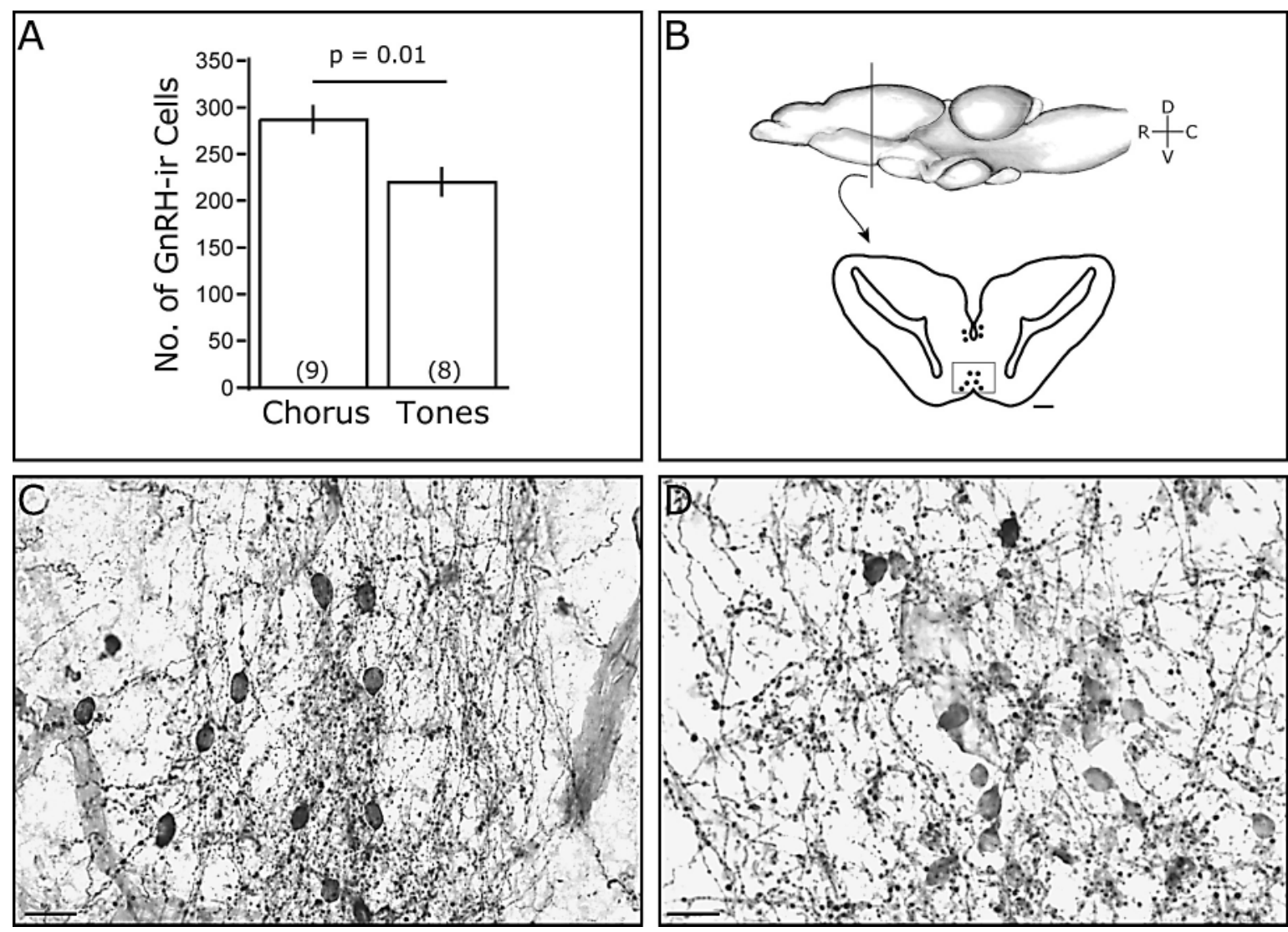

Fig. 1. The effect of acoustic treatment on GnRH immunoreactivity (ir). A The number of GnRH-ir cells (estimated marginal mean \pm $\mathrm{SE}$ ) in response to a mating chorus or tones. Sample sizes are indicated in parentheses. B Schematic drawing of a sagittal view of a frog brain, above (C, caudal; D, dorsal; $\mathrm{R}$, rostral; $\mathrm{V}$, ventral), and of a transverse brain section, below, with a box showing the region imaged in panels $\mathbf{C}$ and $\mathbf{D}$. Dots represent location of GnRH-ir cell bodies and scale bar represents $200 \mu \mathrm{m}$. C Representative section of males listening to a chorus; scale bar is $20 \mu \mathrm{m}$. D Representative section of males listening to tones; scale bar is $20 \mu \mathrm{m}$. Representative sections were chosen as follows: we identified the individual whose total number of counted cells was closest to the unadjusted group mean, and we then chose the section that had the most number of cells for that individual.
Males who listened to the mating chorus had more immunoreactive GnRH cells than tone-listening males $\left(\mathrm{F}_{1,6}=13.7, \mathrm{p}=0.01\right.$; fig. 1 ; unadjusted means \pm SE: chorus, $289 \pm 22$; tones, $232 \pm 32$ ). Qualitatively, choruslistening males appeared to have more intense immunoreactive labeling within cell bodies (fig. 1), suggesting that we identified more cells in this group because more cells contained the threshold level of immunoreactivity necessary for detection. In addition, although the interaction was not statistically reliable (stimulus $\times$ time; $F_{1,12}=2.8$, $\mathrm{p}=0.12$ ), we found that the acoustic stimulus also resulted in an increase in androgen levels among choruslistening males $\left(\mathrm{F}_{1,6}=6.9, \mathrm{p}=0.04\right)$, but not among tonelistening males $\left(\mathrm{F}_{1,6}=0.3, \mathrm{p}=0.58\right.$; fig. 2$)$, as has been previously demonstrated [Burmeister and Wilczynski, 2000, 2001].
We did not detect a reliable covariation between GnRH-ir cell number and androgen levels after acoustic treatment $\left(\mathrm{F}_{1,8}=0.75, \mathrm{p}=0.41\right)$ or between $\mathrm{GnRH}$-ir cell number and the change in androgen levels $\left(\mathrm{F}_{1,7}=1.9, \mathrm{p}=\right.$ 0.21 ). Likewise, we did not find a reliable covariation between GnRH-ir cell number and stimulus evoked calling $\left(\mathrm{F}_{1,10}=0.23, \mathrm{p}=0.64\right)$ or spontaneous calling $\left(\mathrm{F}_{1,10}=\right.$ $0.32, p=0.58)$. As previously demonstrated [Burmeister and Wilczynski, 2000, 2001], we found a statistically reliable correlation between spontaneous $(\mathrm{r}=0.60, \mathrm{n}=15$, $\mathrm{p}=0.018)$, but not evoked $(\mathrm{r}=0.29, \mathrm{n}=15, \mathrm{p}=0.29)$, calling rate and androgen levels following acoustic treatment. 


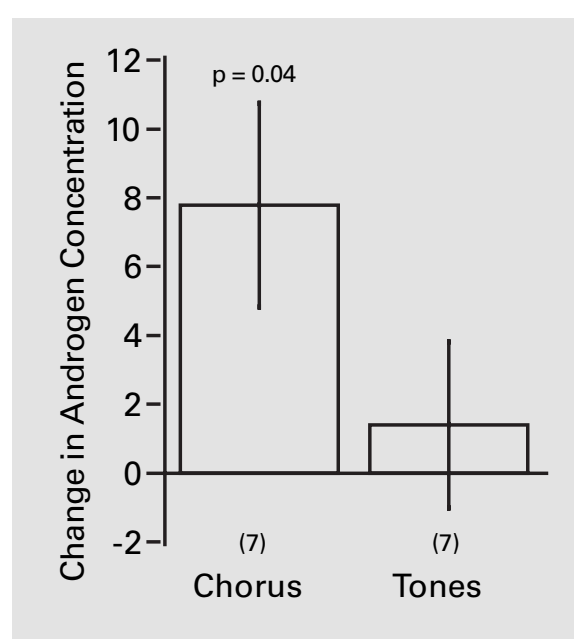

Fig. 2. The change in androgen levels (mean $\pm \mathrm{SE} \mathrm{ng} / \mathrm{ml}$ plasma) in response to the sounds of a mating chorus or tones. Sample size indicated in parentheses.

\section{Discussion}

We found that reception of the mating chorus resulted in more immunoreactive (ir) GnRH cells in the septopreoptic area and increased plasma androgen levels in male green treefrogs (Hyla cinerea), suggesting an overall increase in reproductive capacity. Although a change in immunoreactivity does not by itself give direct information about changes in $\mathrm{GnRH}$ production and release, the fact that androgen levels increased concurrently with increases in GnRH-ir supports the inference that increased GnRH-ir reflects increased production and release of GnRH. Given the well established role of GnRH in control of gonadotropin secretion and gonadotropin effects on gonadal steroid synthesis and release, our findings are consistent with a direct affect of chorus sounds on the GnRH system which subsequently leads to increases in androgen levels. These findings suggest that mating calls are important regulators of reproductive capacity, and that this is accomplished, at least in part, through regulation of the GnRH neurons.

The integration of seasonal environmental cues and behavioral interactions to regulate hormonal state is an important aspect of an organism's life history [Wingfield, 1983; Wingfield et al., 1990]. In seasonally breeding birds [Dawson et al., 2001] and mammals [Ebling and Cronin, 2000], recurrent annual reproduction is tightly controlled by photoperiod, and modified by social cues (e.g., song in birds and pheromones in mammals). In both cases, it appears that seasonality is the product of changes in GnRH secretion, the control of which depends on neural and hormonal inputs. Seasonal changes in HPG activity are often accompanied by changes in the sensitivity of the hypothalamus or pituitary to negative feedback from gonadal secretions [Tilbrook et al., 1999]. In anurans, which are ectotherms, breeding appears to be influenced by photoperiod, temperature and rainfall [Delgado et al., 1992; Saidapur and Hoque, 1995]. Unfortunately, very few details of the mechanisms of seasonal changes in reproductive capacity are understood in anurans. However, what is known from mammals and birds provides a useful framework in which to understand seasonal and social changes in the anuran HPG axis.

We assume that abiotic environmental cues, and not social cues, initiate the seasonal reactivation of the anuran HPG axis, as seasonal changes in physiology must precede formation of the mating chorus, given that androgens are required for call production [Wetzel and Kelley, 1983; Burmeister and Wilczynski, 2001]. In our experiments, males were caught during the breeding season and then housed in the laboratory with long days and warm temperatures, which results in a decline of HPG activity over the course of weeks [Burmeister and Wilczynski, 2000]. The sounds of mating calls are able to restore high activity of the HPG axis under these conditions [Burmeister and Wilczynski, 2000; this study]. This suggests a positive feedback relationship among hearing calls, androgen levels, and call production that could play an important role in maintaining reproductive capacity during the breeding season. This positive feedback relationship is likely tempered by negative feedback of gonadal steroids on HPG activity [McCreery and Licht, 1984]. We propose, therefore, that abiotic seasonal cues initiate the annual reactivation of the HPG axis and, once a threshold of HPG activity is exceeded, social cues, when present, may extend the breeding season and, when absent, may shorten it (fig. 3). The widespread ability of mating calls to influence reproductive physiology suggests that this model may be broadly applicable to anurans [Brzoska and Obert, 1980; Chu and Wilczynski, 2001; Lea et al., 2001].

The regulation of reproductive physiology by $\mathrm{GnRH}$ action on the pituitary is a trait shared by all vertebrates, and $\mathrm{GnRH}$ neurons are a primary site for regulation of the HPG axis [Gore, 2002]. In green treefrogs, as in other vertebrates, social effects on the HPG axis are reflected by changes in GnRH neurons [Propper and Moore, 1991; Francis et al., 1993; Dellovade and Rissman, 1994] or secretion of gonadotropins [Cheng et al., 1998]. Although 


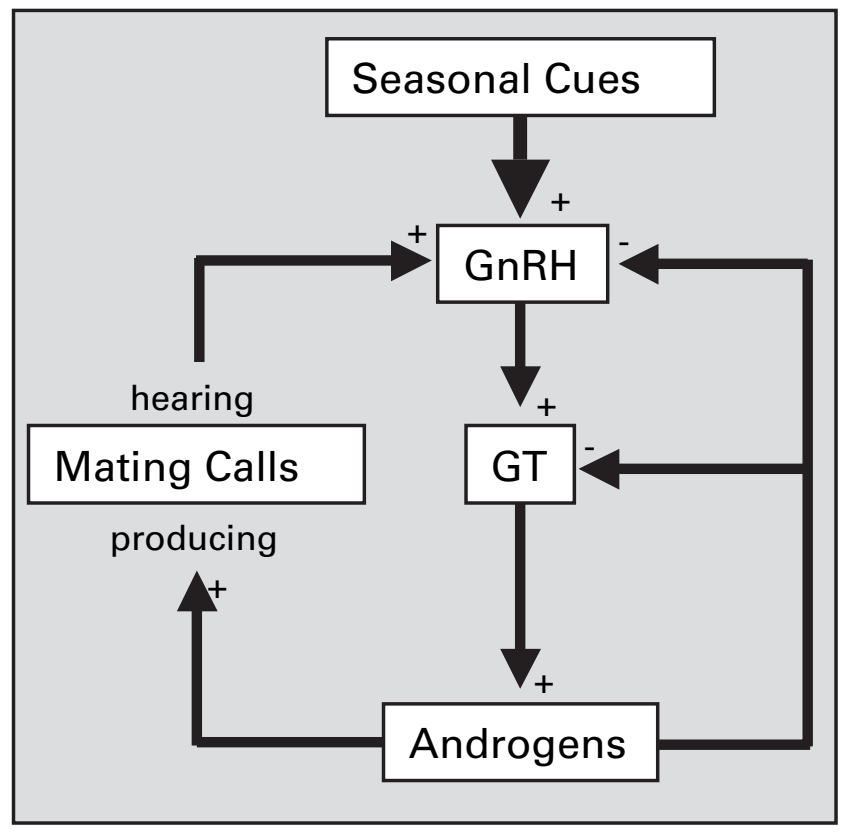

Fig. 3. A proposed model for regulation of the anuran hypothalamuspituitary-gonad (HPG) axis during the breeding season. In the model, seasonal cues initiate the annual reactivation of the GnRH neurons which are further stimulated during the breeding season by hearing mating calls. GnRH neurons regulate androgen levels through their action on gonadotropin (GT) release from the pituitary. Androgens, in turn, exert negative feedback on the HPG axis. Androgens also influence brain regions that increase the production of mating calls, creating a positive feedback loop between the communication system and the endocrine system.

much remains unresolved about social regulation of $\mathrm{GnRH}$ in anurans, we have a relatively clear idea of how the GnRH neurons might receive information about the social environment. In frogs, social cues are mediated by the acoustic domain, and it has been well established that the anuran auditory system projects to GnRH control regions of the brain, specifically, the ventral hypothalamus and the preoptic area (fig. 4) [Neary, 1988; Wilczynski, 1988; Allison and Wilczynski, 1991; Wilczynski et al., 1993]. The ventral hypothalamus, in particular, receives robust projections from two auditory sources, the auditory thalamus (central nucleus) and a midbrain auditory region, the secondary isthmal nucleus. This convergence of auditory projections is reflected by the fact that a third to half of hypothalamic neurons change their electrophysiological activity in response to a conspecific mating call [Wilczynski and Allison, 1989; Allison, 1992].

Although it is not known if the GnRH cells themselves receive acoustic information, studies have demonstrated

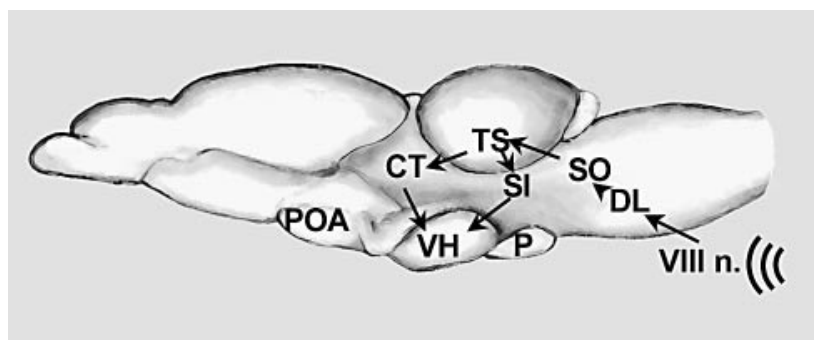

Fig. 4. Primary projections of the ascending auditory system of anurans. The POA also receives projections from CT and SI, although these are less robust than those observed for VH. Abbreviations: CT, central thalamus; DL, dorsolateral nucleus; TS, torus semicircularis; $\mathrm{P}$, pituitary; POA, preoptic area; SI, secondary isthmal nucleus; SO, superior olivary nucleus; VIII n., eighth cranial nerve; VH, ventral hypothalamus.

a possible connection between the auditory system and GnRH neurons; in ranids, the ventral hypothalamus projects to septal areas [Neary, 1988; Sanchez-Camacho et al., 2003], and lesions to the hypothalamus disrupt gonadotropin release [Ball, 1981]. Such studies prompted speculation that acoustic signals could reach GnRH neurons [Neary, 1988; Wilczynski et al., 1993]. Our results provide functional evidence for such a sensory-endocrine circuit by showing that acoustic signals influence GnRH neurons. Furthermore, our studies [Burmeister and Wilczynski, 2000, 2001; this study] reveal the biological relevance of these auditory projections to $\mathrm{GnRH}$ control regions and place this sensory-endocrine circuit within the context of the animal's natural history.

\section{Acknowledgements}

We received assistance from Sunny K. Boyd with immunocytochemistry and Kathleen Lynch with tissue collection. Gregory F. Ball provided logistical support during data collection. We received helpful comments from Anna K. Greenwood and Keith W. Sockman during manuscript preparation. This research was supported by grants to SSB (NIMH T32 MH1 8837 and Society for Integrative and Comparative Biology Grants-in-Aid-of-Research) and WW (NIMH R01 MH57066). 


\section{References}

-Allison JD (1992) Acoustic modulation of neural activity in the preoptic area and ventral hypothalamus of the green treefrog (Hyla cinerea). $\mathrm{J}$ Comp Physiol A 171:387-395.

Allison JD, Wilczynski W (1991) Thalamic and midbrain auditory projections to the preoptic area and ventral hypothalamus in the green treefrog (Hyla cinerea). Brain Behav Evol 38: 322-331.

Ball JN (1981) Hypothalamic control of the pars distalis in fishes, amphibians, and reptiles. Gen Comp Endocrinol 44:135-170.

Brooke PN, Alford RA, Schwarzkopf L (2000) Environmental and social factors influence chorusing behaviour in a tropical frog: examining various temporal and spatial scales. Behav Ecol Sociobiol 49:79-87.

-Brzoska J, Obert H-J (1980) Acoustic signals influence the hormone production of the testes in the grass frog. J Comp Physiol 140:25-29.

Burmeister SS, Wilczynski W (2000) Social signals influence hormones independently of calling behavior in the treefrog (Hyla cinerea). Horm Behav 38:201-209.

Burmeister SS, Wilczynski W (2001) Social context influences androgenic effects on calling in the green treefrog (Hyla cinerea). Horm Behav 40: $550-558$.

Cheng M-F (1986) Female cooing promotes ovarian development in ring doves. Physiol Behav 37:371-374.

Cheng M-F, Peng JP, Johnson P (1998) Hypothalamic neurons preferentially respond to female nest coo stimulation: demonstration of direct acoustic stimulation of luteinizing hormone release. J Neurosci 18:5477-5489.

-Chu J, Wilczynski W (2001) Social influences on androgen levels in the Southern leopard frog, Rana sphenocephala. Gen Comp Endocrinol 121:66-73.

Dawson A, King VM, Bentley GE, Ball GF (2001) Photoperiodic control of seasonality in birds. J Biol Rhythms 16:365-380.

Delgado MJ, Alonsogomez AL, Alonsobedate M (1992) Role of environmental-temperature and photoperiod in regulation of seasonal testicular activity in the frog, Rana perezi. Can J Physiol Pharmacol 70:1348-1352.

Dellovade TL, Rissman EF (1994) Gonadotropinreleasing hormone-immunoreactive cell numbers change in response to social interactions Endocrinology 134:2189-2197.

Ebersole TJ, Boyd SK (2000) Immunocytochemical localization of gonadotropin-releasing hormones in the brain of a viviparous caecilian amphibian, Typhlonectes natans (Amphibia: Gymnophiona). Brain Behav Evol 55:14-25.
Ebling FJP, Cronin AS (2000) The neurobiology of reproductive development. NeuroReport 11: R23-R33.

Fernald RD, White RB (1999) Gonadotropinreleasing hormone genes: Phylogeny, structure, and functions. Front Neuroendocrinol 20:224240.

Francis RC, Soma K, Fernald RD (1993) Social regulation of the brain-pituitary-gonadal axis. Proc Natl Acad Sci 90:7794-7798.

Gerhardt HC (1987) Evolutionary and neurobiological implications of selective phonotaxis in the green treefrog, Hyla cinerea. Anim Behav 35:1479-1489.

-Gerhardt HC, Daniel RE, Perrill SA, Schramm S (1987) Mating behaviour and male mating success in the green treefrog. Anim Behav 35: 1490-1503.

Gore AC (2002) Gonadotropin-releasing hormone (GnRH) neurons: gene expression and neuroanatomical studies. Prog Brain Res 141:193208.

Hahn TP (1995) Integration of photoperiodic and food cues to time changes in reproductive physiology by an opportunistic breeder, the red crossbill, Loxia curvirostra (Aves, Carduelinae). J Exp Zool 272:213-226.

Hau M (2001) The timing of breeding in variable environments: Tropical birds as a model system. Horm Behav 40:281-290.

Lea J, Dyson M, Halliday T (2001) Calling by male midwife toads stimulates females to maintain reproductive condition. Anim Behav 61:373377.

Lehrman DS (1965) The reproductive behavior of ring doves. Sci Am 211:48-54.

Licht P, Tsai P-S, Sotowska-Brochocka J (1994) The nature and distribution of gonadotropinreleasing hormones in brains and plasma of ranid frogs. Gen Comp Endocrinol 94:186198.

McCreery BR, Licht P (1984) Effects of gonadectomy and sex steroids on pituitary gonadotropin release and response to gonadotropin releasing hormone $(\mathrm{GnRH})$ agonist in the bullfrog, Rana catesbeiana. Gen Comp Endocrinol 54:283297.

Neary TJ (1988) Forebrain auditory pathways in ranid frogs. In: The Evolution of the Amphibian Auditory System (Fritzsch B, Ryan MJ, Wilczynski W, Hetherington TE, Walkowiak W, eds), pp 233-252. New York: John Wiley \& Sons.

Oseen KL, Wassersug RJ (2002) Environmental factors influencing calling in sympatric anurans. Behav Ecol 133:616-625.

Propper CR, Moore FL (1991) Effects of courtship on brain gonadotropin hormone-releasing hormone and plasma steroid concentrations in a female amphibian (Taricha granulosa). Gen Comp Endocrinol 81:304-312.
Rastogi RK, Meyer DL, Pinelli C, Fiorentino M, D'Aniello B (1998) Comparative analysis of GnRH neuronal systems in the amphibian brain. Gen Comp Endocrinol 112:330-345.

Rissman EF (1992) Mating induces puberty in the musk shrew. Biol Reprod 47:473-477.

Saidapur SK, Hoque B (1995) Effect of photoperiod and temperature on ovarian cycle of the frog Rana tigrina (Daud). J Biosci 20:445452.

Sanchez-Camacho C, Pena JJ, Gonzalez A (2003) Catecholaminergic innervation of the septum in the frog: a combined immunohistochemical and tract-tracing study. J Comp Neurol 455: 310-323.

Tilbrook AJ, de Kretser DM, Clarke IJ (1999) Seasonal changes in the negative feedback regulation of the secretion of the gonadotrophins by testosterone and inhibin in rams. J Endocrinol 160:155-167.

van der Westhuizen LA, Bennett NC, Jarvis JUM (2002) Behavioural interactions, basal plasma luteinizing hormone concentrations and the differential pituitary responsiveness to exogenous gonadotrophin-releasing hormone in entire colonies of the naked mole-rat (Heterocephalus glaber). J Zool 256:25-33.

Wetzel DM, Kelley DB (1983) Androgen and gonadotropin effects on male mate calls in South African clawed frogs, Xenopus laevis. Horm Behav 17:388-404.

Wilczynski W (1988) Brainstem auditory pathways in anuran amphibians. In: The Evolution of the Amphibian Auditory System (Fritzsch B, Ryan MJ, Wilczynski W, Hetherington TE, Walkowiak W, eds), pp 209-231. New York: John Wiley \& Sons.

Wilczynski W, Allison JD (1989) Acoustic modulation of neural activity in the hypothalamus of the leopard frog. Brain Behav Evol 33:317324.

Wilczynski W, Allison JD, Marler CA (1993) Sensory pathways linking social and environmental cues to endocrine control regions of amphibian forebrains. Brain Behav Evol 42:252-264.

Wingfield JC (1983) Environmental and endocrine control of avian reproduction: An ecological approach. In: Avian Endocrinology: Environmental and Ecological Perspectives (Mikami S, Homma K, Wada M, eds), pp 265-288. New York: Springer-Verlag.

Wingfield JC, Hegner RE, Dufty Jr. AM, Ball GF (1990) The 'Challenge Hypothesis': theoretical implications for patterns of testosterone secretion, mating systems, and breeding strategies. Am Nat 136:829-846. 